University of Wollongong

Research Online

Faculty of Law, Humanities and the Arts Papers (Archive)

Faculty of Arts, Social Sciences \& Humanities

$1-1-2017$

'Fear' and 'hope' in graphic fiction: the schismatic role of law in an Australian dystopian comic

Cassandra E. Sharp

University of Wollongong, csharp@uow.edu.au

Follow this and additional works at: https://ro.uow.edu.au/lhapapers

Part of the Arts and Humanities Commons, and the Law Commons

Research Online is the open access institutional repository for the University of Wollongong. For further information contact the UOW Library: research-pubs@uow.edu.au 


\title{
'Fear' and 'hope' in graphic fiction: the schismatic role of law in an Australian dystopian comic
}

\author{
Abstract \\ The rise in popularity in recent times of dystopian fiction (particularly among young adults) is reflective of \\ contemporary anxieties about law: the inhumanity of judicial-coercive machinery; the influence of \\ corporate power; the lack of democratic imagination despite the desperate need for political reform; and \\ the threat of order imposed through violence and victimisation. These dystopian texts often tell fear- \\ inducing stories of law's failure to protect; or of law's unsuccessful struggle against unbridled power; or \\ even sometimes of law's 'bastardised' reconstruction. Indeed comics, with their visual and narrative \\ intricacies, thrive on dystopia as a key vehicle for contributing to collective notions of fear and trembling \\ about the future. Yet, at the same time, these texts also contain within them the blueprints for hope-the \\ idea that with transformation, heroic intervention, and/or faith in 'justice', the law will ultimately prevail. \\ Law's ability to be transformed is thus simultaneously portrayed as society's downfall (when manipulated \\ and disrupted), AND as the key to enlivening humanity (when redeemed and restored). This article \\ attempts to understand this schismatic role of law as presented in the recent dystopian comic book \\ series From Above by Australian creator Craig Bruyn. In this series set in futuristic Melbourne, where law \\ has given way to an unaccountable corporate rule, the social divide is made manifest by the absence of \\ 'order', 'law' and 'justice' in certain segments of society, and yet hope in law's return is ever-present. The \\ paper will interrogate expectations of law and justice that is mediated through the complex interaction of \\ fear and hope, and contextualise this within current contemporary anxieties.

\section{Disciplines} \\ Arts and Humanities | Law

\section{Publication Details} \\ C. Sharp, 'Fear' and 'hope' in graphic fiction: the schismatic role of law in an Australian dystopian comic' \\ (2017) 30 (3) International Journal for the Semiotics of Law 407-426.
}


'Fear' and 'Hope' in Graphic Fiction - The schismatic role of law in an Australian dystopian comic

Cassandra Sharp ${ }^{1}$

Abstract: The rise in popularity in recent times of dystopian fiction (particularly among young adults) is reflective of contemporary anxieties about law: the inhumanity of judicial-coercive machinery; the influence of corporate power; the lack of democratic imagination despite the desperate need for political reform; and the threat of order imposed through violence and victimisation. These dystopian texts often tell fear-inducing stories of law's failure to protect; or of law's unsuccessful struggle against unbridled power; or even sometimes of law's 'bastardised' reconstruction. Indeed comics, with their visual and narrative intricacies, thrive on dystopia as a key vehicle for contributing to collective notions of fear and trembling about the future. Yet, at the same time, these texts also contain within them the blueprints for hope - the idea that with transformation, heroic intervention, and/or faith in 'justice', the law will ultimately prevail. Law's ability to be transformed is thus simultaneously portrayed as society's downfall (when manipulated and disrupted), AND as the key to enlivening humanity (when redeemed and restored). This article attempts to understand this schismatic role of law as presented in the recent dystopian comic book series From Above by Australian creator Craig Bruyn. In this series set in futuristic Melbourne, where law has given way to an unaccountable corporate rule, the social divide is made manifest by the absence of 'order', 'law' and 'justice' in certain segments of society, and yet hope in law's return is ever-present. The paper will interrogate expectations of law and justice that is mediated through the complex interaction of fear and hope, and contextualise this within current contemporary anxieties.

Keywords: Dystopia. Neoliberal. Graphic Fiction. Fear. Hope

\section{Introduction}

Dystopian fiction (particularly for the young adult demographic) has had a meteoric rise in popularity. The previous trend that focused on the figure of the vampiric monster or paranormal anti-heroes as a commentary on 'young people's attempts to wrestle with identity' [29: 5], has given way to speculative apocalyptic texts as a 'mechanism for exploring the role of the individual in relation to the community' [29: 5]. Bella Swan has had to compete with the enormously popular Katniss Everdeen

\footnotetext{
${ }^{1}$ Dr Cassandra Sharp, Associate Professor, Law School, Faculty of Law, Humanities and the Arts, University of Wollongong and member of the Legal Intersections Research Centre (LIRC). The author would like to acknowledge and thank Assoc Prof Kieran Tranter for the invitation to contribute to the Seeing Law symposium at which a version of this paper was presented, and her fellow participants for their perceptive comments that strengthened this analysis. In addition, the author is grateful to Thom Giddens and Brett Heino for their thoughtful reviews of subsequent drafts and their helpful insight, and to the anonymous reviewers for their suggestions.

${ }^{2}$ eg Twilight by Stephanie Meyers, Fallen by Lauren Kate or the Mortal Instruments Shadowhunter series by Cassandra Clare.
} 
from Hunger Games (2008), Tris Prior from Divergent (2011), and Thomas from The Maze Runner (2009). Successful film adaptations of these books have recently reflected the increasingly lucrative interest in the dystopian genre, refreshed as it has been for young adult audiences. ${ }^{3}$ Yet, it also reflects the opportunities young adults have to consider and reflect on themes of political violence, threats to communal and individual security, commodification of information, and the impact of social rule. Interestingly, while these recent young adult dystopias are a move away from the neoliberal critiques present in early dystopian fiction, ${ }^{4}$ the stories collectively circulating within this genre are contributing to the provocation of complex issues surrounding protectionism, identity, trust and the role of law in societal regulation. Indeed, because the world we live in often feels like dystopian times, and because it has been argued we live in 'the age of neoliberalism' [16], the popularity of these texts does seem to reflect recurring anxieties about law and its ability to protect; or of law's unsuccessful struggle against unbridled corporate power; or even sometimes of law's bastardised reconstruction. Indeed comics, with their combined visual and narrative intricacies, can thrive on this kind of dystopia as a key vehicle for contributing to these collective notions of fear and trembling about the future.

From Above is one such comic series (see Figure 1), recently produced by an Australian creator Craig Bruyn and set in futuristic Melbourne. ${ }^{5}$

\footnotetext{
${ }^{3}$ The theatrical adaption of The Hunger Games made $\$ 408$ million at the box office and the novels sold 23.5 million copies in the US alone, spending over 160 weeks on the New York Times Bestsellers list (IMDB, 2015).

${ }^{4}$ As Ewan Morrison has stated: 'This generation of YA dystopian novels is really our neoliberal society dreaming its last nightmares about the threat from communism, socialism and planned society.' [25]. For an example of early anti-neoliberal dystopian fiction see for example: Philip K Dick Do Androids Dream of Electric Sheep (1968) which was adapted for screen as Blade Runner in 1982 directed by Ridley Scott.

${ }^{5}$ Craig Bruyn created, wrote and illustrated the entire comic series which at present is comprised of seven issues. Issue 1 was first released in 2013.
} 


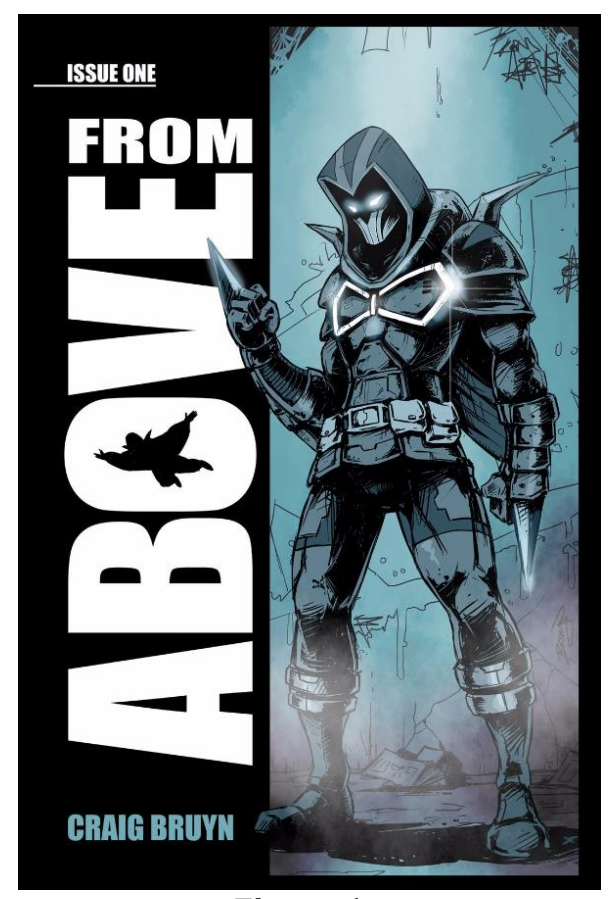

Figure 1

It is a quarterly ongoing, non-capped series that so far, has produced seven issues. It is a world that Bruyn describes as 'a glowing testament to the possibility of ever expanding technological innovation and evolution as a species. ${ }^{6}$ It is a dystopian text that reproduces fear-inducing stories of the inhumanity of judicial-coercive machinery; the influence of corporate power on regulating behaviour; the lack of democratic imagination despite the desperate need for political reform; and the threat of order imposed through violence and victimisation. We are given the setting of this sequential narrative from the back cover of Issue \#1:

A sprawling metropolis built upon the foundations of what was once known as the state of Victoria. Globalisation has seen governments crumble and private corporations have risen to rule and police their own sectors. For those that live within the fortified walls of these corporate utopias life can be good. But for those less fortunate, there just exists a day to day struggle; Trying to eek out an existence in a volatile and dangerous world.

This futuristic world of Melbourne, (strongly reminiscent of Ridley Scott's BladeRunner and more recently Margaret Atwood's MaddAddam trilogy) is depicted as having 'become a society where traditional morality is a long forgotten concept, ${ }^{7}$ and where so very few will take a stand against corruption. It is a place where the corporations have become all-powerful, and are in control of a privatised police force

\footnotetext{
${ }^{6}$ Issue \#4, Back Cover.

${ }^{7}$ Issue \#1, Back Cover.
} 
(including cyber-enhanced mercernaries called 'Alphas') to regulate behaviour and maintain order in each sector.

It is a description of a world that is not too far beyond the imaginings of a critical reader. Particularly with the rise of gated communities, private security details, increasingly policed borders and the threat of capitalism destroying the democratic public sphere, the twenty-first century audience is familiar with pictures inscribed by the neoliberal project. Neoliberal ideas are a very real force in today's global political climate, and evident not only in the universal refugee crisis and its accompanying concerns of statehood, sovereignty and border control, but also in the global economic depression and increasing wealth inequalities. The idea that democracy can lose out to profit - or indeed that social order can be commodified by privatising governmental responsibility - can be fear-inducing. Furthermore, in redefining 'citizens as consumers, whose democratic choices are best exercised by buying and selling' [24], neoliberal orthodoxy often finds expression in disparate wealth communities. Bryn's projected future in From Above is a re-inscription of these ideals, where the corporate elite ignore the advantages of education, inheritance and class that helped to secure their wealth, yet the poor are left to find their own solutions to health care, education and security, while synchronously blaming themselves for their own laziness and failures. This gulf between the privileged few and the deprived is consistently emphasised among the communities of the comic series by the corruption and brutality of the mercenaries who regulate and protect the interests of the corporate elite, and as such, From Above positions the reader to recognise and value the need for change.

As a 'good' super-powered 'Alpha', Gabe has super strength, healing and durability via nanites in his system, thus positioning him effectively to be the very agent of change needed to restore 'justice' and to make a stand against the corporate powers. He wears a body armor suit and hood that contains a retractable airfoil, enabling him to glide through the air above the city, ostensibly 'to protect his employer's interests' [14], which are aligned with bringing safety, social equality and justice back to the segregated communities. Gabe's employer, the mysterious Parker Lockheed, is a strong protagonist who has been shaped by the history of his physical limitations and his drive to advance medico-scientific knowledge and practice. Lockheed himself does not have outstanding powers or talents, but it appears that it is his leadership and guidance, in combination with Gabe's superheroic activities, that provide a glimmer of hope for restoration and equality in this dystopian society. That this is their ultimate mission is reflected in the ongoing story arc of the series, which is the contemporary and familiar issue of people-smuggling as a commodity within the criminal underworld [14]. Finding the villain responsible is the major focus of Gabe's ongoing investigation across issues, evident in his statement that 'in the face of such 
adversity, sometimes there are those who will make a stand for what is just....and their wrath will rain down upon the wicked'.

In this article, I argue that From Above depicts a dystopian society where a centralised, state based rule of 'law' has been usurped by an unaccountable corporate rule, and the social divide is made manifest by the absence of democratic 'order' and/or 'justice' within various segments of society. Moreover, I argue that as this divide is constituted and maintained through the prism of fear perpetuated by the corporations, which resonates within a contemporary landscape that sees both mainstream news media, and popular culture, 'stressing fear and threat as features of entertainment that increasingly are shaping public and private life' [4: 429]. The dystopian text therefore becomes part of a common mass-mediated experience of fear that 'has become a standard frame of reference for audiences, claims makers, and individual actors' [4: 429].

Yet, the argument proffered in this article does not end with simply illustrating the dystopian refraction of real-life issues through the prism of fear - it also analyses the counter-presence of hope in the dystopian design. Although fear is a powerful force that can be manipulated by those in power, hope is equally commanding and offers significant transformative potential. It is my argument that in this dystopian comic, while the law has seemingly been co-opted and bastardised to the detriment of the majority of the populace, embedded within the neoliberal critique of this graphic narrative, are the blueprints for hope - the idea that with transformation, heroic intervention, and/or faith in 'justice', the law can be restored and prevail. As I will show, law's ability to be transformed is thus simultaneously portrayed as society's downfall (when manipulated and disrupted), and as the key to enlivening humanity (when redeemed and restored).

This article will problematize a 'schismatic' role of law presented in Bruyn's uniquely Australian comic book series, by demonstrating the expectations of law and justice that are mediated through the complex interaction of fear and hope. As such, Section II will discuss the nature of fear and hope as presented within the dystopian genre; and Section III will provide a reading of law and justice using From Above as a case study.

\section{Fear and Hope in Dystopian fiction}

The dystopian text is concerned with the design of undesirable civilisations, and particularly within the realm of science fiction, these narratives often 'tend to project a dystopian future' where 'justice' is 'bought and traded by corporate interests' [34:28]. As a direct alternate response to the concept of utopia, dystopias are designed to move the audience to deduce 'what a good civilization is by seeing, in detail, what

\footnotetext{
${ }^{8}$ Issue \#1, Back Cover.
} 
it isn't' [9: 47], and as such speculative fiction with a dystopian turn often presents an absent law or a corrupted justice system as cautionary tales for contemporary society. Dystopias are thus seen as portending the future of humanity, and are what Atwood calls 'dark shadows cast by the present' [8: 94]. Baccolini also writes that as the function of a dystopia 'is to warn readers about the possible outcomes of our present world, [it] entails an extrapolation of key features of contemporary society, [and is] usually located in a negatively deformed future of our own world' [10: 115].

As a critique of existing political or social conditions, dystopian literature typically presents 'an exaggeration of a present social condition or political situation to a nightmarish extreme in a future context' [9: 47]. These dystopian warnings reveal a lack of confidence in the human species, and of the law that is designed to protect them, and they reflect serious anxieties about the future, the purpose of which is to caution against negative directions in human civilisation. ${ }^{9}$ This of course, is resonant with our contemporary 'fatalistic sensibility' [17: 123] in relation to crisis events and human tragedy. ${ }^{10}$ This is a 'not if, but when' sensibility to life that 'co-exists with anxieties concerning the future', and this in turn has the potential to pre-dispose the public to feelings of discomfort managing the various uncertainties of life [17: 123]. ${ }^{11}$ As Margaret Atwood has stated: 'It's a sad commentary on our age that we find dystopias a lot easier to believe in than utopias: utopias we can only imagine; dystopias we've already had' [8: 95]. The dystopian social order text dovetails effectively then with the contemporary rhetoric of fear that is so prevalent through all forms of media and communication. By rhetoric of fear, I am referring to the prevailing and repetitive interactions shaping public expectation that danger, risk and crisis are normalized within everyday life [4: 420]. It is a rhetoric that reflects symbolic relationships about order, danger and threat, and that have 'helped make fear a part of our life, our language, and our point of view.' [5: 2]. It is argued then, that because fear has become an almost natural part of the taken-for-granted expectation of "how things are" and how we view issues of legality and justice, the stories of dystopian fiction speak easily into a public desire to avoid social catastrophe. Both speculative fiction and graphic novels value and utilise this rhetoric by describing and illustrating an easily recognisable future occasioned by rampant capitalism, destruction of liberal freedoms and social catastrophe. As stated earlier, the re-inscription of familiarised possible futures faced by society in such dystopian texts is a common anti-neoliberal vehicle for critiquing what these futures might look like in terms of human identity, community and individual autonomy. As Harmon argues, these texts highlight fears 'that have endured and evolved over long periods of

\footnotetext{
9 'The nature of these social fears changes with the times and dystopias have covered topics that ranged from nuclear disaster, genetic engineering, disease pandemics, environmental disaster, imperialism, capitalism, war, technology, corporate power, media, and so on': [9: 57].

${ }^{10}$ This is particularly the case in relation to issues surrounding terrorism, crime and environmental damage.

${ }^{11}$ Furedi argues that the frequent political message of 'Not If - But When' regarding the threat of terrorism, 'which assumes the form of a "sensible" warning, directly encourages a sense of resignation concerning the inevitability of something bad happening.' [17: 125].
} 
time, and concerns that are only beginning to emerge' in response to various social advancements [19: 76].

The rhetoric of fear successfully pervades the dystopian design precisely because it pervades our quotidian experience, and the critical reader recognizes its major features: the promotion of a sense of disorder and lack of control [4: 420], ${ }^{12}$ and the perpetuation of self-fulfilling prophetic reproductions of fearful interactions. We live in a culture that has institutionalised fear of a Hobbesian 'unknowable harm' [6], ${ }^{13}$ and as such we are easily preconditioned to recognize and propagate fear. As Massumi contends, '(a) threat is only a threat if it retains an indeterminacy' [22: 35]. This integration of fear within our normative assumptions and expectations of everyday life subsequently impacts upon the way we respond to, interpret and discuss events of significance. This is precisely why the rhetoric of fear is often utilized by those in power, as a means for manipulating justice, denigrating the rule of law, and squashing various forms of democratic government. As Nussbaum argues:

Our time is genuinely dangerous. As we have seen, many fears are rational, and appeals to fear have a role to play in a society that takes human life seriously. Still, at this point, the balance has all too often shifted in the other direction, as irresponsibly manufactured fears threaten principles we should cling to and be proud of [26: 244].

As mentioned earlier, dystopian fiction picks up on and exaggerates this pervasive anxiety and fear about the future - by mirroring, tracking and questioning our expectations of justice and law that have already impacted our psyche in recent times. The cumulative impact of fear rhetoric is to reinforce society's consciousness of vulnerability, and 'the more powerless we feel the more we are likely to find it difficult to resist the siren call of fear' [17: 141] The themes of dystopian fiction that represent and cultivate vulnerability become quite effective because they reinforce ideas such as: 'we are all potential victims' or that 'tragedy can erupt at any moment'. This is the essence of Aristotle's argument about the success of perpetual fear:

It follows therefore that fear is felt by those who believe something to be likely to happen to them, at the hands of particular persons, in a particular form, and at a particular time [7].

Yet interestingly and almost contradictorily, dystopian fiction concomitantly offers the opposing emotion of hope, which Aristotle recognized as the way to combat fear. He believed that hope 'is the expectation associated with a mental picture of the

\footnotetext{
${ }^{12}$ In short, the discourse of fear incorporates crime reflexively; whereby the agents, targets, and character of fear are constituted through the [very] processes that communicate fear' [4: 420].

13 'Hobbes recognised how fear could proliferate beyond the objective fact of a distant danger and be transformed in the minds of the public into a pending, inevitable threat.... [it is when the population is instilled with a] sense of dread of an unknown and yet-to-be-experienced collective harm.' [6: 269] See also [17: 133 and 28].
} 
nearness of what keeps us safe and the absence or remoteness of what is terrible: it may be due either to the near presence of what inspires confidence or to the absence of what causes alarm' [7]. The presence of hope, is one key characteristic of what's termed 'critical dystopias', in that they 'allow both readers and protagonists to hope by resisting closure' [12: 7]. It is my argument that the hope in the dystopian world comes from the possibility of law's (re)transformation or return, and a renewed confidence in the future. And so, a mutability of law (from absence to presence; from denial to acceptance; from subduer to redeemer) can be identified in dystopian graphic fiction, whereby it simultaneously produces the contradictory emotions of fear and hope. In this way, I argue that From Above, provides us with the opportunities to explore how fear and hope are visualised within the aesthetic future of law.

\section{The World in From Above}

Within the world of dystopian texts, From Above sit comfortably within the sub-genre of what is classified as 'social order' texts. Generally speaking, 'social order texts address the tensions between the need for individual freedom and the needs of society' [9: 57]. ${ }^{14}$ As the fictional usurpers of power 'present their dogmatic propaganda, readers of social order texts have the opportunity to think critically about the nature of justice, democracy, and societal and individual rights' [9: 57]. In social order texts, the new way of life after a social disaster or radical change is established before the narrative begins, in that they 'begin directly in the terrible new world ... [and the] focus is frequently on a character [or group] who questions the dystopian society' [12: 5].

From Above presents a picture of this type of social order dystopia - it is a future world that depicts an 'inexhaustible and dehumanized state in which controls have been forced upon society and its inhabitants through social and physical limitations' [29: 3] imposed by the corporations that restrict many aspects of life:

Sectorised communities and corporate governance protect and pamper the privileged few, whilst the less fortunate are left to feed off the dregs left behind. $^{15}$

The highly regulated and hierarchical social order frequently depicted in these types of dystopian texts [13: 12] is evident in From Above where overbearing enforcement imposed by the oppressive corporations, are so strong that all but the privileged few have lost the ability to control their own lives and identity. This of course, is a key aspect to neoliberal ideology - to eliminate the concepts of public good and

\footnotetext{
${ }^{14}$ The literature suggests that in young adult fiction, there are three main categories of representing dystopia: the "adventure/quest" text; the "survivor" text; and the "social order" text: see generally [9] and [13].

${ }^{15}$ Issue \#4, Back Cover.
} 
community in favour of individual responsibility and privatization. Gabe and Lockheed's story is therefore played out against this critical backdrop of corporate greed and social injustice. After seven issues, there is still so much to be developed and explained about the catalytic nature and extent of the globalization that precipitated this particular dystopian society, however it is clear that unfettered capitalism and the unrestrained greed that underpins it, was instrumental.

In the most recent release, Issue \#7, the viewer is taken back 12 years into the past, to glimpse Parker Lockheed's drive to develop nanotechnology for both his own physical healing, and for the benefit of humanity. As with most social order texts, the precipitating disasters or crises are actually attempts at greater societal improvement, but the reader has already been positioned across the first 6 issues in this series, to critique this neoliberalist society by recognising that aligning with a corporate military in order to fund development for advancements has significant negative consequences for individual autonomy, freedom, and for the notion of 'being human'. In this way, the anti-neoliberal positioning of the series makes manifest the oppositional forces of fear and hope as Gabe and Lockheed attempt to combat the greed, corruption and social inequality that exists in this world. The visual image of this struggle against human trafficking and enforced slavery via bio-enhancement is illustrated across every page as Gabe engages in violent battles with villains and cybernetically enhanced mercenaries, and it is also seen throughout the wider narrative of abuse of power and the relationship between inequality and justice.

In From Above, the vivid black and white imagery sets the tone of the dystopian world of futuristic Melbourne from the very first issue, which begins with a superhero throwdown - a familiar battle between good and evil. The fast-paced narrative immerses you into this futuristic world of Melbourne almost immediately, with the first Issue introducing not only the main heroes (Gabe and Lockheed) and their motivations, but also the shadowy villain (the Primarch) who 'appears to be pulling the strings from afar' [14]. By the end of the first issue, [see Figure 2] the scope of this dystopian world 'blows out and we see that there is more than just broken metacarpels and rattled teeth on the line' [20]. 


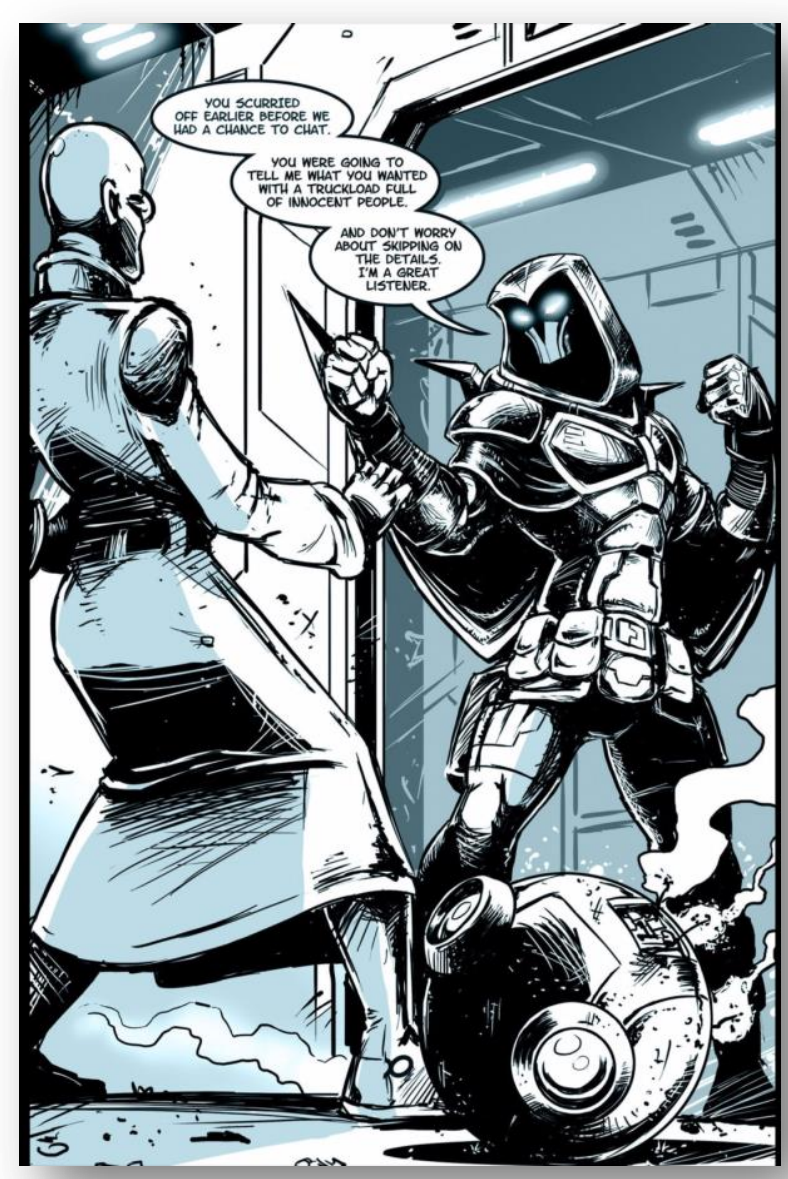

Figure 2

It is a tale about the collapse of traditional government and the rise of corporate power; and the value of hope is illustrated and narrated through the prism of slave distribution, people smuggling, and cyber enhancement. It is clear that human identity has been marginalized in this world, with the series thus far clearly depicting a society where individuals are technologically transformed through many techniques (some voluntary, others forced) including cloning, infusion of nanites into the genetic code for enhancement; and the integration of computer software into human action and movement.

This is a common trope within speculative dystopian texts where law 'has become a commodity to be stockpiled and utilised by corporations' [34: 29]. This reliance on bio-technology and the impact of cyber-enhancement can be read to impliedly indicate the way our society is potentially heading towards unfettered capitalism with an exacerbated impact upon commodification of the body; and the inability of individuals to resist and escape the social inequality that would then be thrust upon them. It is clear that in From Above, the corporations are a social force that protects only their own, and as a result subdues and harshly regulates the rest of the population through the subtle propagation of fear. I say subtle, because we don't visually see the corporations taking part in activities that overtly cause fear - there is no physical violence perpetrated on members of the sectors, nor is there any overt fear-inducing 
activities - however, what we do see in the pages of this graphic fiction are the elements that can contribute to the ongoing perpetuation of fear that are much more nuanced. Indeed, if we view fear as a negative 'affective orientation towards the uncertainties of the future' [1:326], it is possible to expose this orientation as it is contained within the aesthetic detail of From Above. But, equally so, the development of hope, as a counter balance within this society, is also intricately woven into the graphic design.

The remainder of the article will therefore demonstrate the deployment of visual language in From Above to blend 'aesthetic allusions' [36: 15] to produce a nuanced dystopian juxtaposition of the production and circulation of fear via oppressive corporations on the one hand, with the possibility of hope and change through Gabe and Lockheed on the other.

\section{(a) Fear in the Dystopian Picture}

In this burgeoning comic series, Bruyn successfully depicts a fluid and detailed dystopian world that is at once familiar and contradictory, and consequently disturbing. The designs and artwork are detailed, and often busy. Bruyn leads your 'eye across the page. ... through motion, zipping along diagonals... and gives you places to pause,' [20] and 'see' the corporate rule in these images. The subtle conditioning of fear by the corporate elite within the segregated communities is visually evident from the first issue [see Figure 3] where the details of the signage surrounding the privatized sectors instruct the reader that only the wealthy are able to live with security and promise of protection, and the those excluded are abandoned to chaos. 


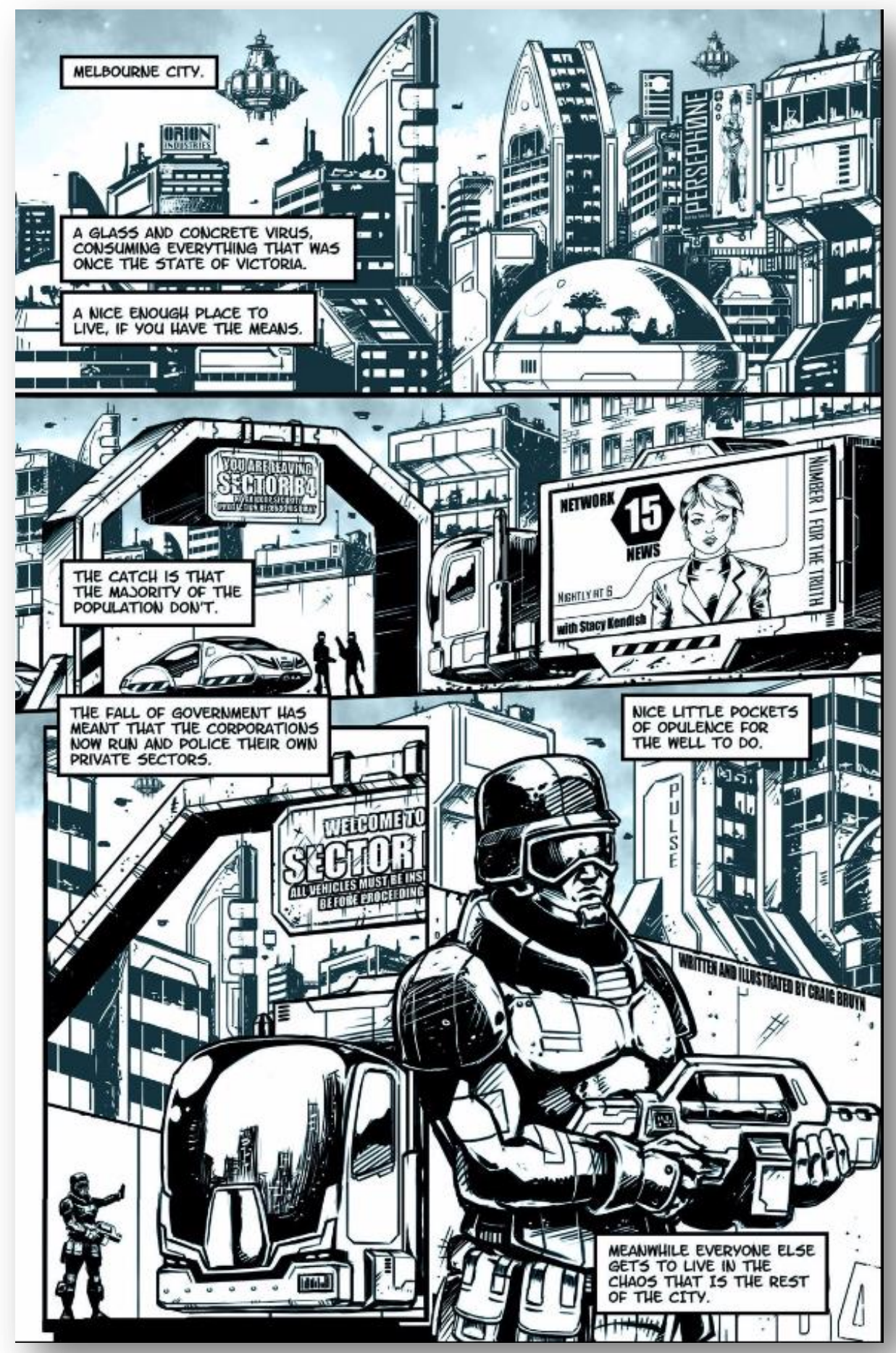

Figure 3

In the ever present image of corporate rule, these panels are representative of antagonistic and oppressive qualities that perpetuate the 'us $v$ them' mentality. ${ }^{16}$ The regulation, police protection and indeed the very presence of law, is visually evident in the wealthy sectors owned by corporations - but it is never visible in the other

\footnotetext{
${ }^{16}$ This is what enables Gabe to operates as the vigilante or hero - offering hope within the dystopian world - see Section III(b).
} 
sectors - in fact the underprivileged sectors are rarely depicted unless they are the sites of struggle and corruption. They are where Gabe fights to uncover the secrets of the human trafficking, and where shady characters conduct their business but the neofuedalist corporate rule is always depicted as that which protects only those inside the walls of their fortresses and is designed to exclude the lower social classes. These proprietary zones of exclusion reflect what Agamben identified as the location for homines sacri or human beings existing in a 'bare life' [35: 244]. That is, the visual depiction of this exclusion - that is the images of the 'non-subjects stripped of every right and living under a palpable threat of death' - invites the adoption of the 'us $v$ them' mentality by emotionally aligning the reader with a shared attribution of evil, or guilt, or greed as the 'other' that is endangering what is 'ours' [23: 203]. This evil other threatens to diminish and destroy what 'we' so dearly possess and value in our contemporary life: a legitimate 'just' world. In this way, the dystopian aesthetic (re)circulates 'recurrent... polemics, rationalities' [23: 203] and stories of 'othering' that contributes to a shared expectation and assumption around law's role as protector.

This 'othering' as evident in the visual dichotomy between the wealthy and poor can be demonstrated by an example from a series of panels in Issue \#4 that describe the recording of a reality style documentary on life in the 'gritty underbelly of some of these older sectors and the lives led by the citizens of these contested zones':

Melbourne City. A glorious hub of cultural diversity and technological innovation. It is a magnificent reflection of our achievements as an ever evolving species. And yet, also in many ways it is a shattered mirror of this broken into so many fragments...for every sector that glistens with the polish of corporate governance, there exists three more that live under the uncertainty of fueding monarchy.

This series of panels is narrated by a celebrity - Hugh Von Rictor - star of Vidcast Sector 22 Blue - as part of his 'community service' seemingly demanded by the corporate law as punishment for drunken behaviour. We can see in these panels that while a privatized law of protection is a presence in the corporate sector, 'law' is completely absent 'down in the dirt' (see Figure 4). 


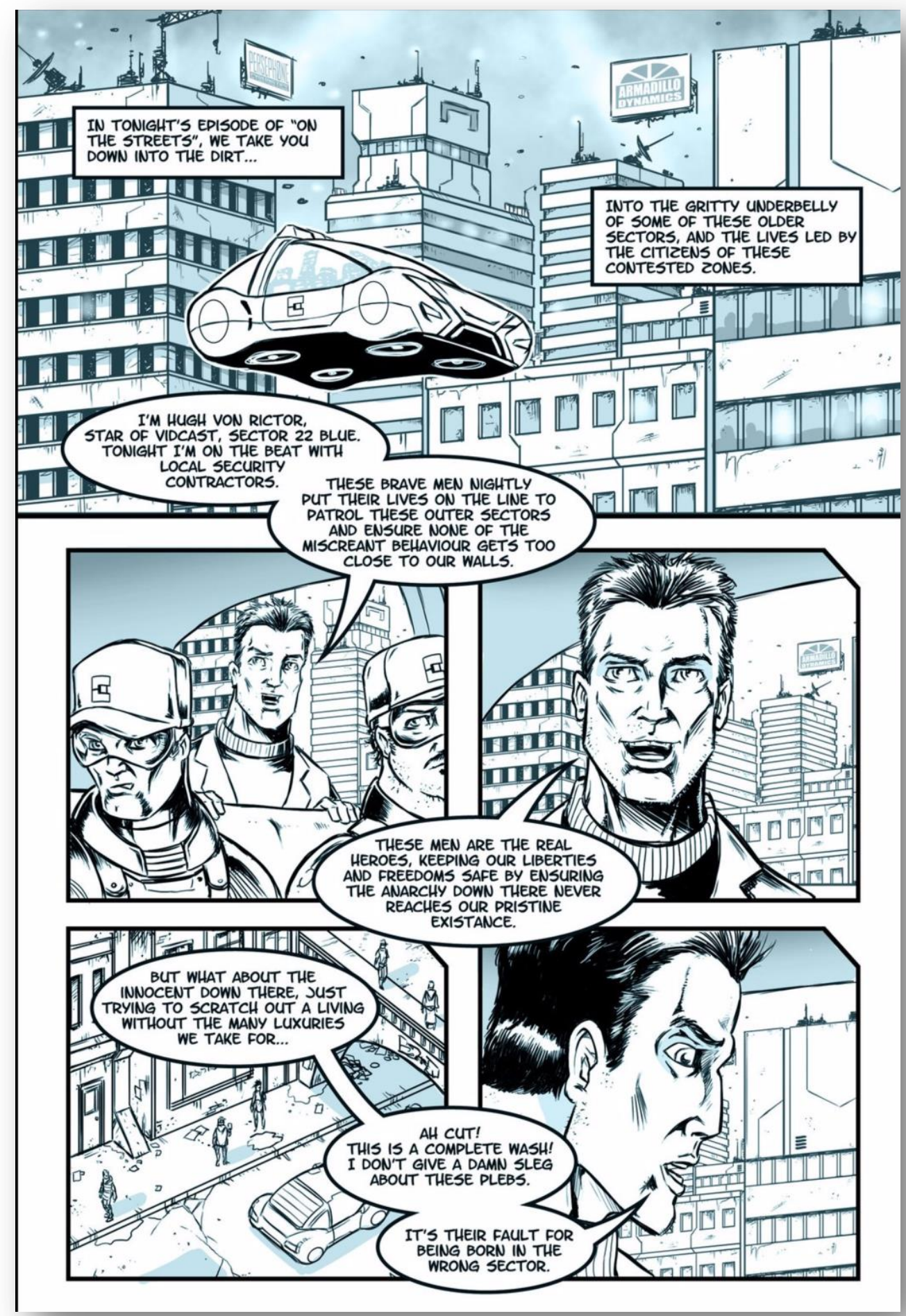

Figure 4

Quite clearly, the security contractors from the corporate sectors, seen by the wealthy as 'the real heroes', 'patrol' the outer sectors in an attempt to ensure that the miscreants in those sectors do not impact upon their 'pristine existence'. Again the existence of the underprivileged is invisibilised - the reader is left to imagine that these regular patrols provide the necessary indicia that will increase vigilance and heighten sensitivity to a perceived threat. It is in this issue that we also discover that 
citizenship in a given sector is dependant on one's birthplace, and so, the corporations rule those 'who were simply born in the wrong sector' by constituting a threatening presence.

This aesthetic of fear created by the social inequity is also contained within the juxtaposition of the image of the cybernetically weaponised 'evil corporate other', and the concept of the 'innocent victim'. This innocence is visually represented in the vulnerability of Gracie (a little girl growing up in this world), and in the fear in the faces of those most at disadvantage [see Figures $5 \& 6$ ], that is those people who had been kidnapped and intended for bio-slavery.

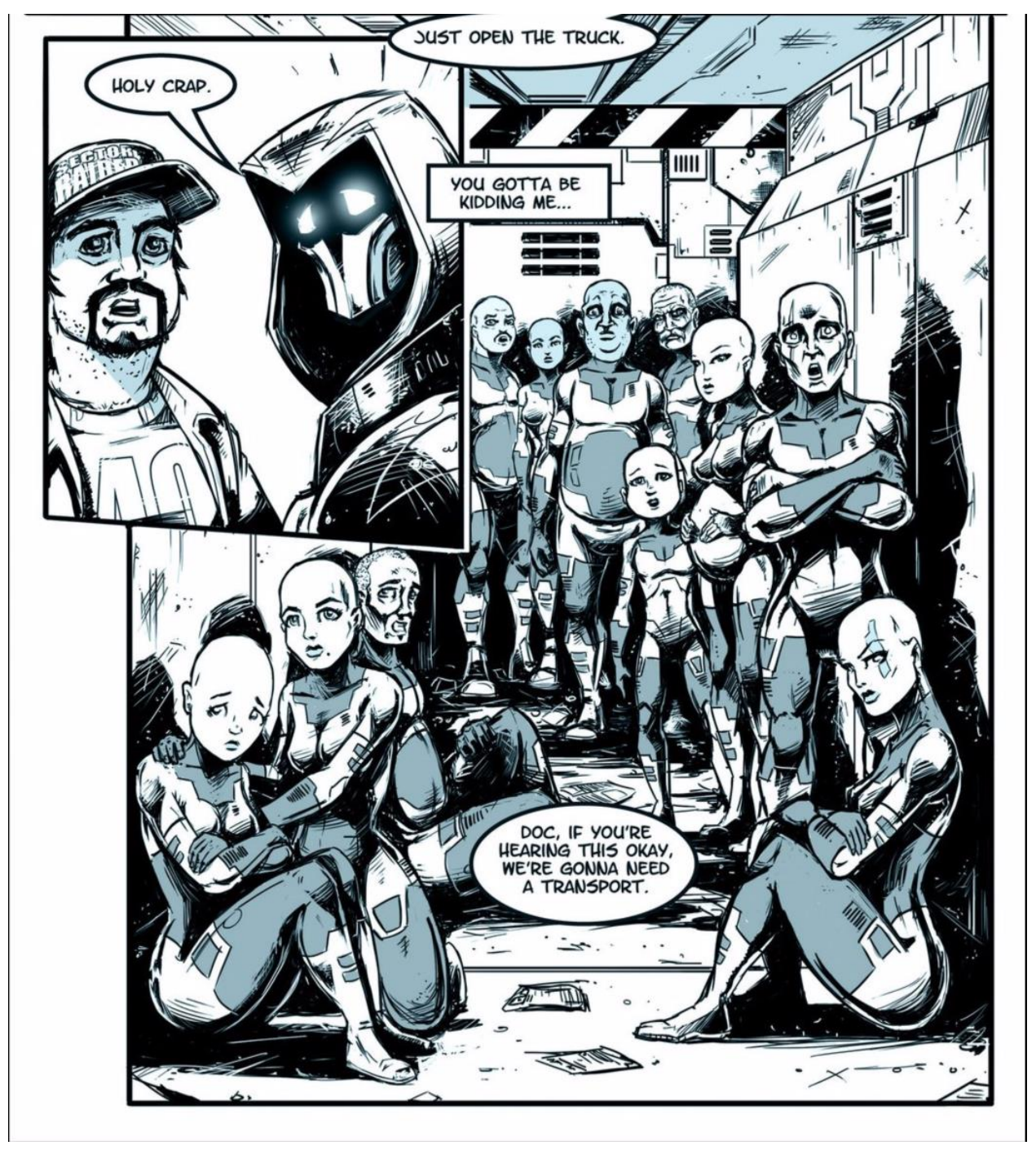

Figure 5 


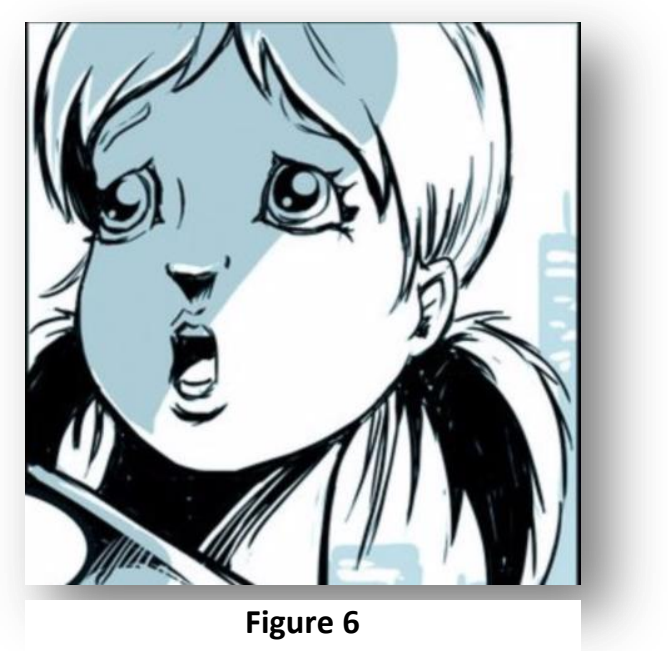

In these rare moments, we 'see' representatives of the disadvantaged. They are finally visible - yet they are under threat, or extremely vulnerable - and these visual elements have significant persuasive appeal because they enhance the narrative of a collective innocent and threatened 'us' in relation to a malevolent and destructive 'them', which works to fortify a worldview that values social justice and the need of restoration by the hero. In combination, the aesthetic and narrative 'othering' contributes to the development of a 'certain rage against these illegitimate others...' [3: 2] and it is exactly the fragility and vulnerability of our just world that provokes expectations of law and justice within the public imagination. The visual aesthetic of fear is manifested in widespread perception of powerlessness, which in turn provokes a questioning of the legitimacy of the law, and its ability to cope with and/or withstand threatening events or forces. And so despite living in marginalised conditions, Gabe stages acts of resistance against the illegitimate 'state' power - the corporations - to win back safety and security for those who need it most, to eradicate the disparity between the economic realities of the sectors, and to fight for a restoration of law that had been lost to them.

Integral to the series' dystopian aesthetic which highlights the effects of this disparity, is the choice to draw in black and white - which can be read as presenting dualities of law and lawlessness, truth and propaganda, poverty and riches, and exclusion and inclusion. Furthermore, the starkness of the black/white panels can initially be read as iterating the symbol of undemocratic demarcated authority, and even perhaps the complex interactions of fear and hope. ${ }^{17}$ Yet interestingly, on progression through the series, or on subsequent readings, the ocular gaze focuses less on the stark and detailed use of black and white and more on the transmuted tones of grey. Bruyn's deployment of shading across the panels has powerful persuasive appeal to the reader

\footnotetext{
${ }^{17}$ It is important to note that a blue coloured shading version of the comic is available in digital graphic form (ie on ComiXology) while this is not present in the hard copies. One could argue that this significantly points to the perpetuation of its own type of class distinction where those who can afford the technology (or submit to it), can access not only the 'better' version of the comic, but also 'better' access to hope in our present world.
} 
who is looking for hope in the dystopian design. Within the effective contrast of light and shadow lies the promise and value of hope and viewing the panels as 'grey shading' rather than 'black/white' could be read as illustrating the subtleties of justice and the hope of breaking down barriers that prevent the law from fulfilling its promise.

\section{(b) The picture of dystopian hope}

Law, transformed as it has been by the wealthy corporations in From Above, can be read as disfigured, and absent or inaccessible to the majority of the population, yet it can also be read as holding out hope for the possibilities of redemption. The sense of hope is indeed the driving force for many a protagonist in critical dystopian fiction, which often provides the space for hope by allowing for the potential that character driven change will succeed. From Above utilizes this critical dystopian trope to encourage hope for social change, by depicting Gabe and Lockheed as agents of transformation and resistance. They are concerned with the liberation of the nonprivileged, and they are symbolic of a desire to liberate law, and for law to liberate all people. The hope or desire present in this series, is for a way of life that is unimpeded, a freedom, a sense of rightful belonging, and social equality.

Yet, it is interesting to note that the space for hope is essentially 'outside' the pages of the story [10: 520]. Only as the ongoing nature of the graphic series resists full closure thereby allowing hope, can the reader identify the utopian impulse contained within the images and narrative [13: 12]. So, promised hope exists in the actions of Gabe and Lockheed and the reader quickly recognizes in the narrative the very human instinctual desire and grasping for social justice within the community. This is an innate desire to hold individuals responsible for their actions, and it feeds into what I have previously argued is an instinctive retributive public imaginary that contains a strong belief that the function and promise of law is to actually provide justice [30]. Hope therefore is made apparent in the desire of Gabe and Lockheed to restablise society, to restore social balance, and to reinstitute law for the benefit of all.

Whereas 'fear tends to induce a profound caution [and] inclines the subject toward risk aversion' [1: 326] hope 'moves with eagerness toward an anticipated future. It is associated with a resourceful, improvisational attitude toward new possibilities' [1: 326] and so Gabe and Lockheed, represent a positive anticipated future within this futuristic Melbourne. As Lockheed himself articulates:

As it stands, the corporate bodies who govern these sectors have gone unchecked for far too long - they have been conducting immoral activities behind well marketed veneers....answerable only to public perception. We plan to make them accountable. (Issue \#3.) 
To attribute blame on the 'evil others' who do not seem to 'get what they deserve' [31] is the mechanism through which From Above demonstrates the justifiable retributive desire of Gabe and Lockheed to effect social change and cultivate hope. Throughout the series they seek to investigate of the human trafficking ring, and bring corporate villainy to justice - and they have done so 'from above'. Picking up on the symbolism of the series title, Gabe and Lockheed operate from within the 'Ark' what is described in Issue \#2 as 'a heavily modified and retrofitted former refuelling platform - [where] its internals [are] cloaked from prying technology making it a sanctuary' and home for their little unit [see Figure 7].

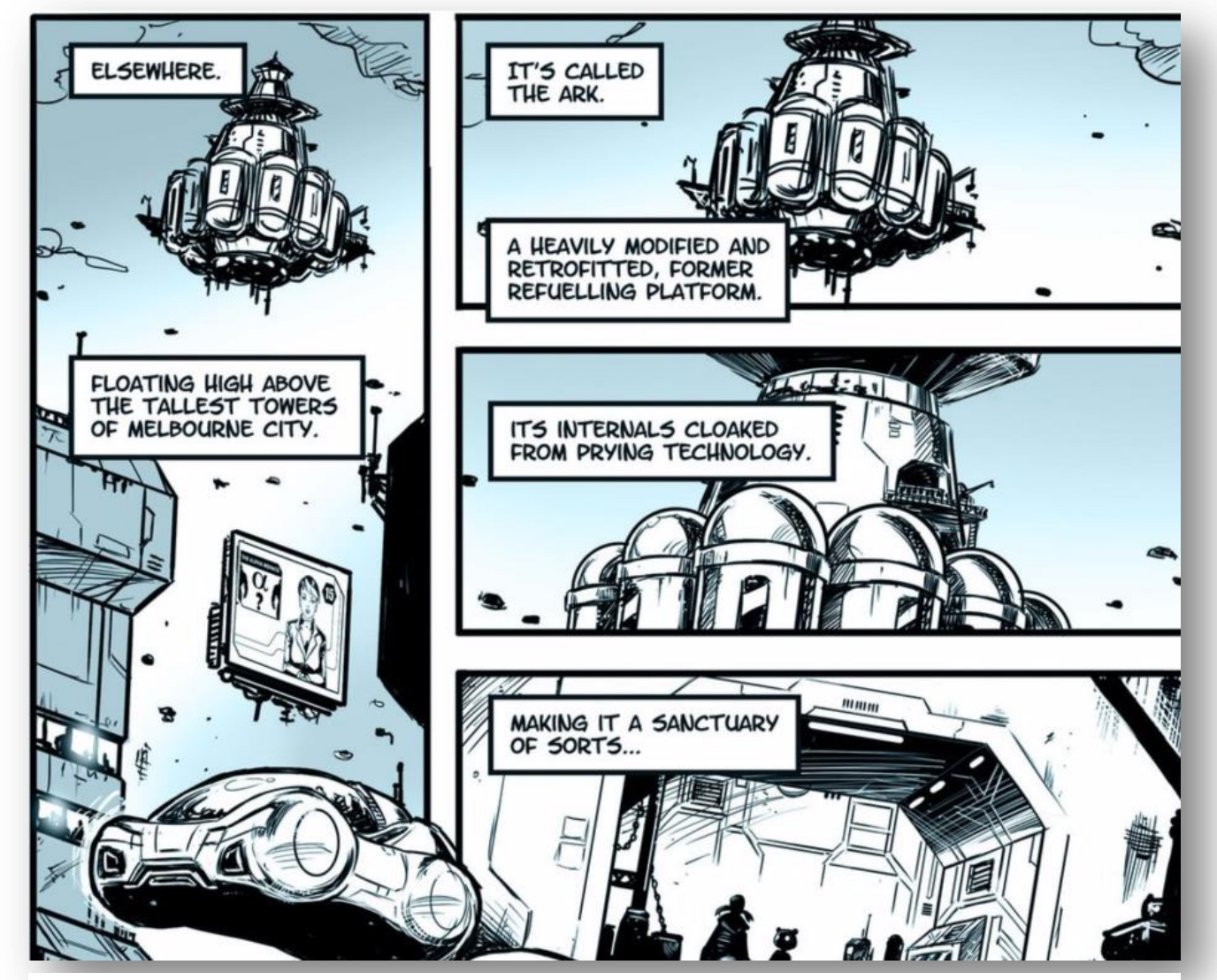

Figure 7

Indeed, 'floating high above the tallest towers of melbourne city - they live and train on the Ark' (Issue 2), and offer their home as a place of refuge to those whom they have redeemed from slavery. This of course, has biblical undertones - just as Noah's Ark housed and protected the 'innocents' who would repopulate the earth, so too does this Ark represent a chance of redemption and hope. It is from here that Gabe flies down to investigate, and in this sense, redemption and hope both literally and figuratively comes from above [see Figure 8], thereby illustrating the potential of cultivating hope through the transformation of law. 


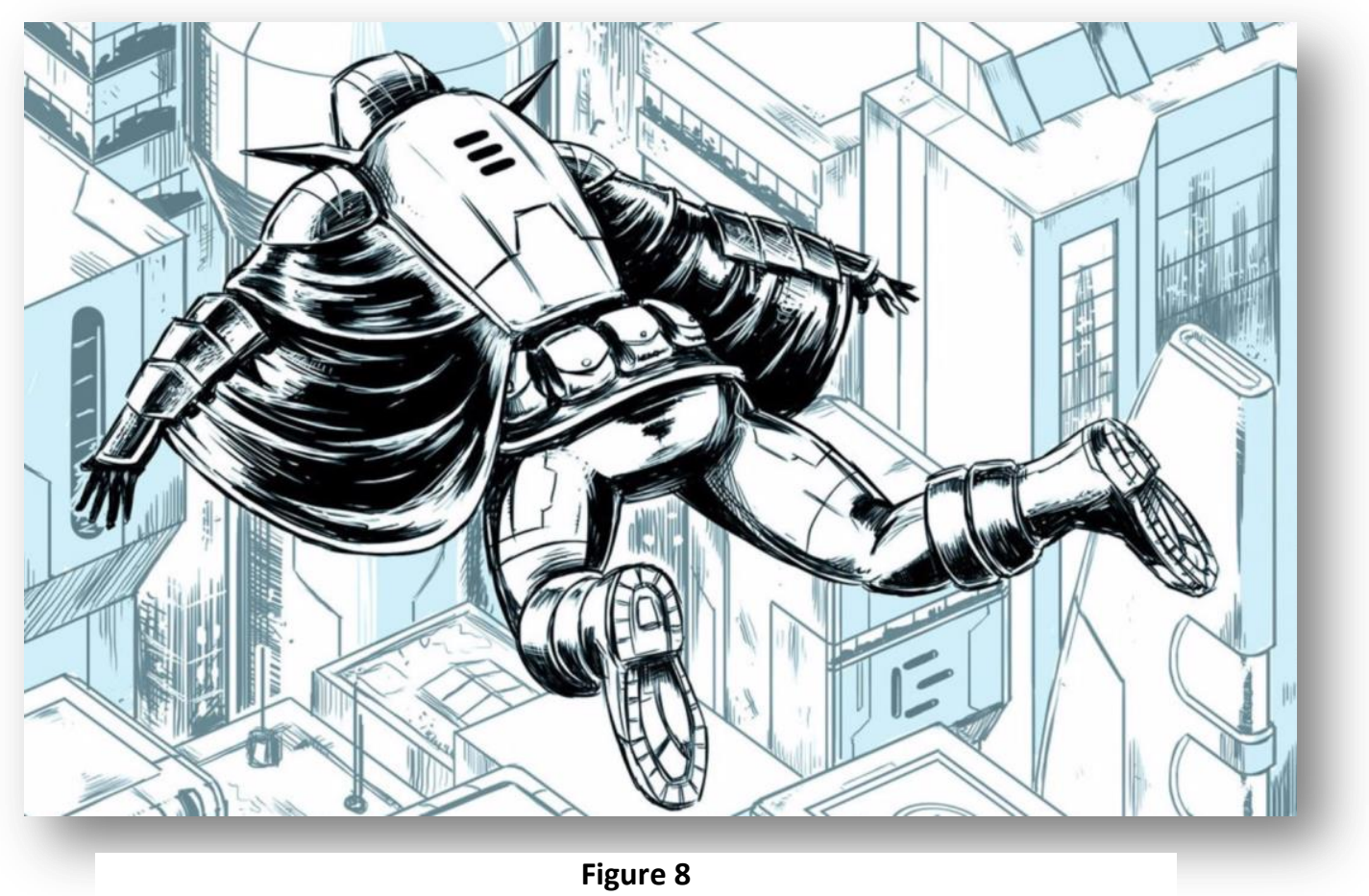

With its immense 'importance for individuals or groups who face material disadvantage, inequality, or despair' [1: 321], a sound cultivation of hope 'has the potential to transform the orientation of its beneficiaries'. As Abrams and Keren argue:

Those energized by hope can fuel and direct the resultant efforts at change, rather than continuing to rely on an impetus that comes from outside.' And that hope, 'is contiguous in its effects. [1:321].

This potential of hope embraced and pursued as a result of sustained exposure to others who are hopeful (or who in themselves provide hope), is cumulatively significant. It would seem that the very existence of the Ark itself predicates a belief that a better future is possible. Their actions from above to care for those sectors that do not have access to law, or who are excluded from privilege, reaches the reader on an emotional level and 'suggest that the legal cultivation of hope may become an ongoing process which has its own momentum, and which continues to produce results long after the investment of initial resources' [1: 322]. Gabe's actions in this series provides those in the abandoned sectors (and the reader) with a goal that while distant, is yet valuable. With the restoration of social justice being seen as 'potentially capable of being achieved' [1:322], it is argued that this series demonstrates the enlivenment of hope.

\section{Conclusion}


I have consistently argued that individuals use stories to frame and contextualise normative expectations of the legal system [32: 33 and 33]. This is even more so with graphic fiction, because it provides the added complexity and nuances of the visual. ${ }^{18}$ In graphic fiction, our reading of legal meaning is constituted in the story we see and read. Operating as another popular 'cultural source of law's authority and legitimacy' and as a way of 'apprehending [legal] knowledge by sensuous means', [18: 15] From Above provides a uniquely pictorial narrative of the connection between social justice, fear and hope as experienced aesthetically in the transformative action of the law. ${ }^{19}$

\section{References}

1. Abrams, Kathryn and Hila Keren, 2007. Law in the Cultivation of Hope. California Law Review. 95(3): 319.

2. Agamben, G. 1998. Heller-Roazen, trans. Homo Sacer: Sovereign Power and Bare Life Stanford, CA: Stanford University Press.

3. Ahmed, Sara. The Cultural Politics of Emotion, (Edinburgh: Edinburgh University Press, 2004): 2

4. Althiede, David. 2006. Terrorism and the Politics of Fear. Cultural Studies: Critical Methodologies, 6(4): 415.

5. Althiede, David. 2006. Terrorism and The Politics of Fear. Oxford UK: AltaMira Press.

6. Aly, Anne and Lelia Green. 2010. Fear, Anxiety and the State of Terror. Studies in Conflict and Terrorism. 33: 269.

7. Aristotle. Rhetoric. Translated by W Rhys Roberts. 2004. Book II Chapter 5 1383a. New York: Dover Publications.

8. Atwood, Margaret. 2005. Writing Utopia. Writing with Intent: Essays, Reviews, Personal Prose: 1983-2005. New York: Carroll and Graf Publishers: 94.

9. Baker, Kaline Elizabeth. 2015. Media As A Social Institution: The Power Dynamics Of Media In The Young Adult Dystopian Fiction Of M.T. Anderson And Suzanne Collins. Masters Thesis: University of British Columbia.

10. Baccolini, Raffaella. 2003. "A Useful Knowledge of the Present Is Rooted in the Past": Memory and Historical Reconciliation in Ursula K. Le Guin's The Telling, in Baccolini, Raffaella and Tom Moylan. 2003. eds. Dark Horizons: Science Fiction and the Dystopian Imagination. New York and London: Routledge: 113-134.

\footnotetext{
${ }^{18}$ Narratives of law also extend into the future in normative projections of their effects. As Cover writes: 'A nomos, as a world of law, entails the application of human will to an extant state of affairs as well as toward our visions of alternative futures' [15: 7].

19 'Nothing remains untouched by the aesthetic temperament...not even that most ostensibly rational of human endeavours, the law' [21:24].
} 
11. Baccolini, Raffaella. 2004. The Persistence of Hope in Dystopian Science Fiction in Special Topic: Science Fiction and Literary Studies: The Next Millennium, PMLA. 119(3): 518-521.

12. Baccolini, Raffaella and Tom Moylan. 2003. eds. Dark Horizons: Science Fiction and the Dystopian Imagination. New York and London: Routledge.

13. Braithwaite, Elizabeth. 2010. Post-disaster fiction for young adults: some trends and variations. Papers: explorations into children's literature. 20(1): 519.

14. Close, Darren. 2016. Review of From Above \#1, online Australian Comics Journal. http://australiancomicsjournal.com/?p=2106, last accessed 19 June 2016.

15. Cover, Robert M. 1983. The Supreme Court, 1982 Term - Forward: Nomos and Narrative. Harvard Law Review 97:4.

16. Frodeman, Robert, Adam Briggle and J. Britt Holbrook. 2012. Philosophy in the Age of Neoliberalism. Social Epistemology. 26:3-4, 311-330,

17. Furedi, Frank. 2003. The Politics of Fear. UK: Continuum Press.

18. Gomez-Romero, Luis and Ian Dahlmann. 2012. Introduction - Justice Framed: law in comics and graphic fiction. In Law Text Culture 16:3-32.

19. Harmon, Shawn HE. 2015. Not foresighting, not answering: using graphic fiction to interrogate social and regulatory issues in biomedicine. In Graphic Justice: Intersections of Comics and Law, ed Thomas Giddens, 71-88. London: Routledge.

20. Lindsay, Ryan. 2015. Foreward to the Collected Volume From Above (Issues 1-6) on ComiXology.

21. Manderson, Desmond. 2000. Songs without Music: Aesthetic Dimensions of Law and Justice. Berkeley: University of California Press.

22. Massumi, Brian. 2005. Fear (the Spectrum Said). Positions. 13(1): 35.

23. Matthews, Julie. 2005. Visual Culture and Critical Pedagogy in "Terrorist Times". Discourse: studies in the cultural politics of education. 26(2): 203224.

24. Monibot, George. 2016. Neoliberalism - the ideology at the root of all our problems. The Guardian Books. Friday 15 April 2016, https://www.theguardian.com/books/2016/apr/15/neoliberalism-ideologyproblem-george-monbiot

25. Morrison, Ewan. 2014. YA dystopias teach children to submit to the free market, not fight authority, The Guardian: Books, 1 September 2014, https://www.theguardian.com/books/2014/sep/01/ya-dystopias-children-freemarket-hunger-games-the-giver-divergent

26. Nussbaum, Martha. 2012. The New Religious Intolerance: Overcoming the Politics of Fear in an Anxious Age. Harvard University Press.

27. Peck, Jamie. 2010. Constructions of Neoliberal Reason. New York: Oxford.

28. Robin, Corey. 2004. Fear: The History of a Political Idea. Oxford: Oxford University Press. 
29. Ryan, Devin. 2014. Emerging Themes in Dystopian Literature: The Development of an Undergraduate Course. Honors Theses, Lee Honors College, Western Michigan University, Paper 2466.

30. Sharp, Cassandra 2015. Finding Stories of Justice in the Art of Conversation: Ethnography in Cultural Legal Studies in Sharp, Cassandra and M Leiboff. Eds. 2015. Cultural Legal Studies: Law's Popular Cultures and the Metamorphosis of Law. UK: Routledge.

31. Sharp, Cassandra. 2014. Justice with a Vengeance - Retributive Desire in Popular Imagination. In Asimow, Michael eds. 2014. Law and Popular Culture: International Perspectives. US: Cambridge Scholars Publishing.

32. Sharp, Cassandra. 2011. "Represent a Murderer...I'd Never do That!" How Students use Stories to Link Ethical Development and Identity Construction. In Robertson, Michael et al. eds. 2011. The Ethics Project in Legal Education. Routledge: 33.

33. Sharp, Cassandra. 2005. The "Extreme Makeover" Effect of Law School: Students being Transformed by Stories. Texas Wesleyan Law Review 12(1):233.

34. Travis, Mitchell and Kieran Tranter. 2014. Interrogating absence: the lawyer in science fiction. International Journal of the Legal Profession 21(1): 23-37.

35. Vials, Chris. 2015. Margaret Atwood's dystopian fiction and the contradictions of neoliberal freedom. Textual Practice 29(2): 235-254.

36. Warren, Matthew. 2012. The Future Past: Intertextuality in Contemporary Dystopian Video Games. Submitted for the Macaulay Honors College Thesis Colloquim. 